\title{
Impact of incretin-related agents on endothelial cell function
}

\author{
Hiroshi Nomoto ${ }^{1}$, Hideaki Miyoshi1, *, Akinobu Nakamura1, Tatsuya Atsumi', Naoki Manda², Yoshio Kurihara ${ }^{3}$, \\ Shin Aoki ${ }^{4}$, on behalf of SAIS Study Group ^
}

\author{
1 Division of Rheumatology, Endocrinology and Nephrology, Hokkaido University Graduate School of Medicine, Sapporo, Japan \\ 2 Manda Memorial Hospital, Sapporo, Japan \\ 3 Kurihara Clinic, Sapporo, Japan \\ 4 Aoki Clinic, Sapporo, Japan \\ ^ The membership of the SAIS Study Group is provided in the Acknowledgements. \\ *Correspondence to: Hideaki Miyoshi, M.D., Ph.D., hmiyoshi@med.hokudai.ac.jp. \\ orcid: 0000-0002-5909-3243 (Hideaki Miyoshi)
}

\section{Abstract}

Incretin-related drugs, such as dipeptidyl peptidase-4 (DPP-4) inhibitors and glucagon-like peptide-1 (GLP-1) analogues, have been clinically available and widely used to treat patients with type 2 diabetes mellitus. Accumulating evidence indicates that these agents exert glycemic control and have various other favorable effects, including prevention of atherosclerosis. It is important to assess and manage early-phase atherosclerosis, but whether diabetic therapeutics including incretin-related drugs improve or maintain vascular endothelial cell function has not been fully determined. We previously published prospective clinical trials focused on flow-mediated dilation in patients with type 2 diabetes, who did not have severe atherosclerosis, using two different incretin-related drugs: a DPP-4 inhibitor and a GLP-1 analogue. These trials showed that these therapeutic agents did not improve endothelial cell function. In this article, we discuss how incretin-related drugs contribute, if at all, to vascular endothelial cell function, atherosclerosis, and beta-cell function, based on our clinical trials and previous evidence.

Key words: GLP-1 analogue; DPP-4 inhibitor; endothelial cell function

doi: $10.4103 / 2542-3975.202726$

How to cite this article: Nomoto H, Miyoshi H, Nakamura A, Atsumi T, Manda N, Kurihara Y, Aoki S, on behalf of SAIS Study Group. Impact of incretin-related agents on endothelial cell function. Clin Trials Degener Dis. 2017;2(1):7-11.

Open access statement: This is an open access article distributed under the terms of the Creative Commons Attribution-NonCommercial-ShareAlike 3.0 License, which allows others to remix, tweak, and build upon the work non-commercially, as long as the author is credited and the new creations are licensed under the identical terms.

Funding: This work was supported by The Japan Diabetes Foundation Inc. and The Waksman Foundation of Japan Inc.

\section{INTRODUCTION}

Prevention of atherosclerotic diseases, such as cardiovascular disease (CVD) and stroke is an issue that should be resolved in patients with type 2 diabetes mellitus because they have a higher risk of these conditions.1 Recent comprehensive care of patients with risk factors dramatically decreased diabetic macro- and microvascular complications, ${ }^{2}$ but the mortality rate is still higher in populations with diabetes. ${ }^{3}$ Therefore, detection and management of the earlier phases of atherosclerosis is important. It has been reported that endothelial cell damage precedes progressive atherosclerosis and these dysfunctions are known to be individual risk factors for CVD in type 2 diabetes mellitus., ${ }^{4,5}$ For the relationship between therapeutics and endothelial cell function, numerous studies have been performed, and statins $^{6}$ and angiotensin II receptor blockers7 along with some anti-diabetic agents were reported to improve endothelial dysfunction. ${ }^{8,9}$

In recent years, incretin-related drugs such as dipeptidyl peptidase-4 (DPP-4) inhibitors and glucagon-like peptide-1 
(GLP-1) analogues, have been available to treat patients with type 2 diabetes mellitus and their anti-atherosclerotic potentials had been expected based on many in vitro studies and animal models. However, some longitudinal studies failed to verify their superiority for the prevention of CVD. ${ }^{10-12}$ Moreover, their effects on endothelial cell function have been inconsistent. ${ }^{13}$ We performed two different randomized controlled trials that focused on endothelial cell function, using different incretin-related agents, the DPP-4 inhibitor sitagliptin and the GLP-1 receptor agonist liraglutide. Results of these clinical trials demonstrated that both medications did not improve endothelial cell function assessed by flow-mediated dilatation. Here, we will introduce them and discuss the effects of incretin-related therapy on the early phase of atherosclerosis.

\section{The Effect of Incretin-Related Therapy on Endothelial Cell Function}

We investigated whether incretin-related drugs improve endothelial cell function using flow-mediated dilatation (FMD) of the brachial artery. FMD is known to be a less-invasive tool that reflects endothelial nitric oxide bioavailability to evaluate endothelial cell function, and a reversible marker of early phase of atherosclerosis. ${ }^{14}$ Additionally, a recent meta-analysis showed that improvement of FMD was significantly related to the relative risk reduction in cardiovascular events. ${ }^{15}$ Thus, treatments that have favorable effects on FMD might be ideal for prevention form cardiovascular outcomes. We conducted two open-label, multicenter, prospective randomized parallel-group comparison studies comparing sitagliptin versus glimepiride (SAIS-1) ${ }^{16}$ and liraglutide versus insulin glargine (SAIS-2) ${ }^{17}$ (Table 1). Briefly, patients with type 2 diabetes mellitus who did not have severe atherosclerotic diseases were randomly assigned to each treatment, and underwent treatment for 26 or 14 weeks, respectively. FMD and biochemical assessment were performed before and after the treatment periods, and all FMD measurements were conducted under controlled conditions by a well-trained technician who was blinded to the study to minimize the introduction of potential confounding variables. For FMD, neither sitagliptin nor liraglutide affected endothelial cell function in this treatment periods, and neither did glimepiride and glargine (Table 2). Some previous clinical trials suggested that GLP-1 analogues and DPP-4 inhibitors improved FMD, ${ }^{18-20}$ but there is some controversy including the lack of a control group, the study duration, the subject populations, and FMD measurement accuracy. Assessment of FMD is so sensitive that the results were greatly affected by many internal and environmental factors, such as patients' background (sex, age, obesity, heart rate and smoking), ${ }^{21}$ conditions (air temperature, mental/physical stress), ${ }^{22-24}$ and the medications described above. There were opposing results and opinions about the relationship between incretin agents and FMD results. ${ }^{25,26}$ Our studies fully controlled these confounding factors and both treatment groups were similarly controlled for glycemic metabolism. Moreover, another assessment method for endothelial dysfunction, End-PAT, also showed the same results. A recent metaanalysis revealed that efficacy of GLP-1-based therapies on FMD was confirmed only in cross-sectional studies but not in longitudinal studies. ${ }^{13}$ It was reported that native GLP-1 infusion for several hours to individuals with type 2 diabetes resulted in improvement in endothelial function..$^{27,28}$ Although both GLP-1 and cleaved GLP-1, such as GLP-1(9-36) and GLP-1(28-36), may cause these effects, a study comparing the effect of native GLP-1 on vascular function with or without of sitagliptin to prevent an increase of the cleaved form of GLP-1 resulted in no detectable changes in both groups. ${ }^{29}$ Although the existence of the GLP-1 receptor on the vascular endothelium has been suggested, recent accumulating evidence showed that the endothelium does not possess the GLP-1 receptor, ${ }^{30,31}$ but there is currently no consensus. Thus, beneficial effects of incretin-related therapy on atherosclerotic changes may be mainly explained by indirect mechanisms rather than by direct action on endothelial cells.

\section{Effects on Beta-Cell Function and Atherosclerosis} Incretin-related agents exert glucose-lowering effects in a blood glucose-dependent manner, ${ }^{32}$ and they also play an important role in avoiding hypoglycemia by diminishing insulin secretion and preventing glucagon secretion under normal-to-hypoglycemic conditions. ${ }^{33}$ Numerous in vitro and animal model experiments verified protective and proliferative effects of incretin-related agents on pancreatic beta-cells, and our prospective studies also demonstrated that both a DPP-4 inhibitor and a GLP-1 analogue showed incremental beta-cell functions, assessed by surrogate markers of insulin secretion (Table 2). Similarly, some clinical trials using incretin agents clarified incremental beta-cell function. ${ }^{34,35}$ Effects of a GLP-1 analogue on beta-cell signaling include activating adenylate cyclase/protein kinase A, phosphatidylinositol 3-kinase/Akt, and the adenosine monophosphate kinase/mTOR cascades, which results in proliferation of beta-cells in rodents. However, the precise signaling of GLP-1 analogues has not been fully determined in humans. ${ }^{36}$ Additionally, pancreatic beta-cells are known to be sensitive to oxidative stresses that result from relatively low expression levels of anti-oxidant enzymes, such 


\begin{tabular}{lll}
\hline \multicolumn{2}{l}{ Table 1: Inclusion criteria and outline of the original studies } & \\
\hline & SAIS-1 & SAIS-2 \\
\hline Primary endpoint & Change in flow-mediated dilation. \\
Design & Multicenter, prospective, randomized, parallel-group & \\
Age (years) & 20 to 75 & 20 to 70 \\
Number of patients & 110 & 30 \\
HbA1c (\%) & 6.9 to 8.4 & 7.4 to 10.5 \\
Previous treatment & Metformin or none & Metformin and/or Sulphonylurea \\
Treatment arms & Sitagliptin $50 \mathrm{mg} /$ day or Glimepiride $0.5-2.0 \mathrm{mg} /$ day & Liraglutide 0.9 mg/day or Insulin glargine \\
Treatment periods (weeks) & 26 & 14 \\
\hline
\end{tabular}

Note: HbA1c: Hemoglobin A1c; SAIS-1: Sapporo athelo-incretin study-1; SAIS-2: Sapporo athelo-incretin study-2.

\section{Table 2: Summary of the original studies}

\begin{tabular}{|c|c|c|c|c|}
\hline \multirow[b]{2}{*}{ Levels of HbA1c } & \multicolumn{2}{|l|}{ SAIS-1 } & \multicolumn{2}{|l|}{ SAIS-2 } \\
\hline & Sitagliptin & Glimepiride & Liraglutide & Glargine \\
\hline$\%$ FMD & $\downarrow$ (Improved) & $\downarrow$ (Improved) & $\downarrow$ (Improved) & $\downarrow$ (Improved) \\
\hline Inflammatory markers (TNF- $\alpha, \mathrm{d}-\mathrm{ROMs})$ & $\downarrow$ (Improved) & $\rightarrow$ & $\downarrow$ (Improved) & $\rightarrow$ \\
\hline Anti-oxidant responses (SOD, BAP) & $\uparrow$ (Improved) & $\rightarrow$ & $\rightarrow$ & $\rightarrow$ \\
\hline Lipid profiles (adiponectin, HDL-C) & $\uparrow$ (Improved) & $\rightarrow$ & $\rightarrow$ & $\rightarrow$ \\
\hline Beta-cell functions (SUIT, C-peptide index) & $\uparrow$ (Improved) & $\uparrow$ (Improved) & $\uparrow$ (Improved) & $\rightarrow$ \\
\hline Cardiovascular markers (AI, NT-proBNP) & $\rightarrow$ & $\rightarrow$ & $\downarrow$ (Improved) & $\rightarrow$ \\
\hline
\end{tabular}

Note: HbA1c: Hemoglobin A1c; SAIS-1: Sapporo athelo-incretin study-1; SAIS-2: Sapporo athelo-incretin study-2; FMD: flow-mediated dilation; TNF- $\alpha$ : tumor necrosis factor alpha; d-ROMs: reactive oxygen metabolites-derived compounds; SOD: superoxide dismutase; BAP: biological antioxidant potential; HDL-C: high-density lipoprotein cholesterol; SUIT: secretary units of islets in transplantation; AI: augmentation index; NTproBNP: N-terminal pro-brain natriuretic peptide.

as superoxide dismutase, catalase, and glutathione peroxidase. ${ }^{37}$ GLP-1 exerts anti-oxidant effects via suppression of nitric acid synthase expression in pancreatic beta-cells. ${ }^{38}$ DPP-4 inhibitors were reported to reduce apoptosis in pancreatic beta-cells ${ }^{39,40}$ and induce anti-oxidant responses, ${ }^{41}$ and such mechanisms might be beneficial for protection of beta-cells from some kinds of stresses.

In addition, long-term administration of these agents showed favorable effects on anti-oxidant, anti-atherosclerotic, and lipid metabolism in our study. One of the DPP-4 inhibitors, sitagliptin, ameliorated HDL-cholesterol via increasing adiponectin, anti-oxidant responses, and serum TNF- $\alpha$ levels. However, the GLP-1 analogue, liraglutide, caused a reduction of oxidative stress and improvement in cardiac load and atherosclerosis (Table 2). Incretinrelated drugs including DPP-4 inhibitors have been shown to have favorable effects on atherosclerosis via mediating several pathways, attenuating TNF- $\alpha$-mediated induction of plasminogen activator inhibitor- 1 expression, ${ }^{42}$ preventing reactive oxygen species-induced cell senescence in endothelial cell lines,${ }^{43}$ increasing serum adiponectin lev- els, ${ }^{44}$ suppressing macrophage-related inflammation, and inhibiting DPP-4-induced smooth muscle proliferation..$^{45}$.

Despite these many favorable mechanisms, many clinical trials using DPP-4 inhibitors failed to show their superiority to placebo in CVD outcomes. ${ }^{10-12}$ One of the possible reasons is that these trials mainly included patients with atherosclerotic diseases. Therefore, even such potent agents may not be enough to suppress advanced atherosclerotic diseases. Earlier intervention may be beneficial for patients with early-phase atherosclerosis.

\section{Conclusions}

Accumulating evidence suggests that incretin-based therapy has anti-atherosclerotic effects and favorable effects on pancreatic beta-cells. However, the long-term results on endothelial cell function have not yet been determined. Our clinical trials provided direct evidence that these agents did not improve endothelial cell function in patients with type 2 diabetes, although their favorable effects on beta-cells and atherosclerosis are expected and will be assessed in the future. 
8. Papathanassiou K, Naka KK, Kazakos N, et al. Pioglitazone vs glimepiride: Differential effects on vascular endothelial function in patients with type 2 diabetes. Atherosclerosis. 2009;205:221-226.

HM, AN, and TA have received honoraria for lectures from Astellas Pharma Inc., AstraZeneca, Dainippon Pharma Co., Eli Lilly, Kissei, Mitsubishi Tanabe Pharma Co., MSD, Novo Nordisk Pharma, Chugai Pharmaceutical Co., Sanofi, Takeda Pharmaceutical Co., Ltd, Pfizer Inc., and AbbVie Inc., and have received research funding from Astellas Pharma Inc., AstraZeneca, Eli Lilly, Mitsubishi Tanabe Pharma Co., Chugai Pharmaceutical Co., Ltd, Daiichi Sankyo Co., Ltd, and Otsuka Pharmaceutical Co., Ltd.

Author contributions

$\mathrm{HN}$ and HM designed the original study. HN contributed to the writing the manuscript. HM and TA revised the manuscript. All authors contributed to enrollment of patients and approved the final manuscript.

\section{Acknowledgments}

These studies received grant funding from The Japan Diabetes Foundation Inc. and The Waksman Foundation of Japan Inc. and were conducted by the SAIS study group. The SAIS study group consists of the Division of Rheumatology, Endocrinology and Nephrology, Hokkaido University Graduate School of Medicine, First Department of Medicine of Hokkaido University, Clark Hospital, Ogasawara Clinic Sapporo Hospital, Ohtsuka Eye Hospital, Hokkaido Social Insurance Hospital, Yuri Ono Clinic, Manda Memorial Hospital, Kurihara Clinic, and Aoki Clinic.

Plagiarism check

This paper was screened twice using CrossCheck to verify originality before publication.

Peer review

This paper was double-blinded and stringently reviewed by international expert reviewers.

\section{ReFEREnCES}

1. Sarwar N, Gao P, Seshasai SR, et al. Diabetes mellitus, fasting blood glucose concentration, and risk of vascular disease: a collaborative meta-analysis of 102 prospective studies. Lancet. 2010;375:2215-2222.

2. Gregg EW, Li Y, Wang J, et al. Changes in diabetes-related complications in the United States, 1990-2010. N Engl J Med. 2014;370:1514-1523.

3. Lind M, Garcia-Rodriguez LA, Booth GL, et al. Mortality trends in patients with and without diabetes in Ontario, Canada and the UK from 1996 to 2009: a population-based study. Diabetologia. 2013;56:2601-2608.

4. Beckman JA, Creager MA, Libby P. Diabetes and atherosclerosis: epidemiology, pathophysiology, and management. JAMA. 2002;287:2570-2581.

5. Calles-Escandon J, Cipolla M. Diabetes and endothelial dysfunction: a clinical perspective. Endocr Rev. 2001;22:36-52.

6. Takagi H, Yamamoto H, Iwata K, Goto SN, Umemoto T. Low-density lipoprotein-independent improvement of flowmediated dilatation with atorvastatin: a meta-analysis and meta-regression of randomized controlled trials. Int J Cardiol. 2012;158:285-289.

7. Li S, Wu Y, Yu G, Xia Q, Xu Y. Angiotensin II receptor blockers improve peripheral endothelial function: a meta-analysis of randomized controlled trials. PLoS One. 2014;9:e90217.
9. Wascher TC, Schmoelzer I, Wiegratz A, et al. Reduction of postchallenge hyperglycaemia prevents acute endothelial dysfunction in subjects with impaired glucose tolerance. Eur J Clin Invest. 2005;35:551-557.

10. Green JB, Bethel MA, Armstrong PW, et al. Effect of sitagliptin on cardiovascular outcomes in type 2 diabetes. $N$ Engl J Med. 2015;373:232-242.

11. White WB, Cannon CP, Heller SR, et al. Alogliptin after acute coronary syndrome in patients with type 2 diabetes. $N$ Engl $J$ Med. 2013;369:1327-1335.

12. Scirica BM, Bhatt DL, Braunwald E, et al. Saxagliptin and cardiovascular outcomes in patients with type 2 diabetes mellitus. N Engl J Med. 2013;369:1317-1326.

13. Song X, Jia H, Jiang Y, et al. Anti-atherosclerotic effects of the glucagon-like peptide-1 (GLP-1) based therapies in patients with type 2 diabetes Mellitus: a meta-analysis. Sci Rep. 2015;5:10202.

14. Deanfield JE, Halcox JP, Rabelink TJ. Endothelial function and dysfunction: testing and clinical relevance. Circulation. 2007; 115:1285-1295.

15. Inaba Y, Chen JA, Bergmann SR. Prediction of future cardiovascular outcomes by flow-mediated vasodilatation of brachial artery: a meta-analysis. Int J Cardiovasc Imaging. 2010;26:631640.

16. Nomoto H, Miyoshi H, Furumoto T, et al. A randomized controlled trial comparing the effects of sitagliptin and glimepiride on endothelial function and metabolic parameters: Sapporo athero-incretin study 1 (SAIS1). PLoS One. 2016;11:e0164255.

17. Nomoto H, Miyoshi H, Furumoto T, et al. A comparison of the effects of the GLP-1 analogue liraglutide and insulin glargine on endothelial function and metabolic parameters: a randomized, controlled trial Sapporo athero-incretin study 2 (SAIS2). PLoS One. 2015;10:e0135854.

18. Kubota Y, Miyamoto M, Takagi G, et al. The dipeptidyl peptidase-4 inhibitor sitagliptin improves vascular endothelial function in type 2 diabetes. J Korean Med Sci. 2012;27:1364-1370.

19. Noda Y, Miyoshi T, Oe H, et al. Alogliptin ameliorates postprandial lipemia and postprandial endothelial dysfunction in nondiabetic subjects: a preliminary report. Cardiovasc Diabetol. 2013;12:8.

20. Irace C, De Luca S, Shehaj E, et al. Exenatide improves endothelial function assessed by flow mediated dilation technique in subjects with type 2 diabetes: results from an observational research. Diab Vasc Dis Res. 2013;10:72-77.

21. Benjamin EJ, Larson MG, Keyes MJ, et al. Clinical correlates and heritability of flow-mediated dilation in the community: the Framingham Heart Study. Circulation. 2004;109:613-619.

22. Iwata M, Miyashita Y, Kumagai H. Seasonal variation of endothelium-dependent flow-mediated vasodilation measured in the same subjects. Am J Cardiovasc Dis. 2012;2:111-115.

23. Amir O, Alroy S, Schliamser JE, et al. Brachial artery endothelial function in residents and fellows working night shifts. Am J Cardiol. 2004;93:947-949. 
24. Spieker LE, Hurlimann D, Ruschitzka F, et al. Mental stress induces prolonged endothelial dysfunction via endothelin-A receptors. Circulation. 2002;105:2817-2820.

25. Ayaori M, Iwakami N, Uto-Kondo H, et al. Dipeptidyl peptidase-4 inhibitors attenuate endothelial function as evaluated by flow-mediated vasodilatation in type 2 diabetic patients. $J$ Am Heart Assoc. 2013;2:e003277.

26. Hopkins ND, Cuthbertson DJ, Kemp GJ, et al. Effects of 6 months glucagon-like peptide-1 receptor agonist treatment on endothelial function in type 2 diabetes mellitus patients. Diabetes Obes Metab. 2013;15:770-773.

27. Ceriello A, Novials A, Canivell S, et al. Simultaneous GLP-1 and insulin administration acutely enhances their vasodilatory, antiinflammatory, and antioxidant action in type 2 diabetes. Diabetes Care. 2014;37:1938-1943.

28. Nystrom T, Gutniak MK, Zhang Q, et al. Effects of glucagonlike peptide- 1 on endothelial function in type 2 diabetes patients with stable coronary artery disease. Am J Physiol Endocrinol Metab. 2004;287:E1209-1215.

29. Devin JK, Pretorius M, Nian H, Yu C, Billings FTt, Brown NJ. Dipeptidyl-peptidase 4 inhibition and the vascular effects of glucagon-like peptide-1 and brain natriuretic peptide in the human forearm. J Am Heart Assoc. 2014;3.

30. Pyke C, Knudsen LB. The glucagon-like peptide-1 receptor--or not? Endocrinology. 2013;154:4-8.

31. Richards P, Parker HE, Adriaenssens AE, et al. Identification and characterization of GLP-1 receptor-expressing cells using a new transgenic mouse model. Diabetes. 2014;63:1224-1233.

32. Drucker DJ. Incretin action in the pancreas: potential promise, possible perils, and pathological pitfalls. Diabetes. 2013;62:3316-3323.

33. Nauck MA, Kleine N, Orskov C, Holst JJ, Willms B, Creutzfeldt W. Normalization of fasting hyperglycaemia by exogenous glucagon-like peptide 1 (7-36 amide) in type 2 (non-insulindependent) diabetic patients. Diabetologia. 1993;36:741-744.

34. Retnakaran R, Kramer CK, Choi H, Swaminathan B, Zinman B. Liraglutide and the preservation of pancreatic beta-cell function in early type 2 diabetes: the LIBRA trial. Diabetes Care. 2014;37:3270-3278.

35. Leibowitz G, Cahn A, Bhatt DL, et al. Impact of treatment with saxagliptin on glycaemic stability and beta-cell function in the SAVOR-TIMI 53 study. Diabetes Obes Metab. 2015;17:487494.
36. Tuduri E, Lopez M, Dieguez C, Nadal A, Nogueiras R. Glucagon-like peptide 1 analogs and their effects on pancreatic islets. Trends Endocrinol Metab. 2016;27:304-318.

37. Grankvist K, Marklund SL, Taljedal IB. CuZn-superoxide dismutase, Mn-superoxide dismutase, catalase and glutathione peroxidase in pancreatic islets and other tissues in the mouse. Biochem J. 1981;199:393-398.

38. Jimenez-Feltstrom J, Lundquist I, Salehi A. Glucose stimulates the expression and activities of nitric oxide synthases in incubated rat islets: an effect counteracted by GLP-1 through the cyclic AMP/PKA pathway. Cell Tissue Res. 2005;319:221-230.

39. Mu J, Woods J, Zhou YP, et al. Chronic inhibition of dipeptidyl peptidase- 4 with a sitagliptin analog preserves pancreatic betacell mass and function in a rodent model of type 2 diabetes. Diabetes. 2006;55:1695-1704.

40. Kim SJ, Nian C, Doudet DJ, McIntosh CH. Inhibition of dipeptidyl peptidase IV with sitagliptin (MK0431) prolongs islet graft survival in streptozotocin-induced diabetic mice. Diabetes. 2008;57:1331-1339.

41. Shah P, Ardestani A, Dharmadhikari G, et al. The DPP-4 inhibitor linagliptin restores beta-cell function and survival in human isolated islets through GLP-1 stabilization. J Clin Endocrinol Metab. 2013;98:E1163-1172.

42. Liu H, Hu Y, Simpson RW, Dear AE. Glucagon-like peptide-1 attenuates tumour necrosis factor-alpha-mediated induction of plasminogen [corrected] activator inhibitor-1 expression. $J$ Endocrinol. 2008; 196:57-65.

43. Ishibashi Y, Matsui T, Takeuchi M, Yamagishi S. Sitagliptin augments protective effects of GLP-1 against advanced glycation end product receptor axis in endothelial cells. Horm Metab Res. 2011;43:731-734.

44. Hibuse T, Maeda N, Kishida K, et al. A pilot three-month sitagliptin treatment increases serum adiponectin level in Japanese patients with type 2 diabetes mellitus--a randomized controlled trial START-J study. Cardiovasc Diabetol. 2014;13:96.

45. Ervinna N, Mita T, Yasunari E, et al. Anagliptin, a DPP-4 inhibitor, suppresses proliferation of vascular smooth muscles and monocyte inflammatory reaction and attenuates atherosclerosis in male apo E-deficient mice. Endocrinology. 2013;154:12601270 . 